\section{Integration of oral health into primary health care system: views of primary health care workers in Lagos State, Nigeria}

\author{
Matilda Braimoh, ${ }^{1}$ Eyitope Ogunbodede, ${ }^{2}$ \\ Abiola Adeniyi ${ }^{3}$ \\ 1Dental Department, Lagos State \\ University Teaching Hospital, Ikeja; \\ ${ }^{2}$ Department of Preventive and \\ Community Dentistry, Obafemi Awolowo \\ University; ${ }^{3}$ Department of Preventive \\ Dentistry, Lagos State University College \\ of Medicine, Nigeria
}

\section{Abstract}

The limited access to oral health care in developing countries can be greatly improved by integrating oral health into the Primary Health Care (PHC) system. This study was designed to assess the views of PHC workers on integrating oral health care into the PHC system. A self-administered questionnaire survey was conducted in two selected local government areas of Lagos State. The instrument contained three sections assessing sociodemographic features, knowledge of common oral diseases and views on integration of oral health into $\mathrm{PHC}$ respectively. The mean knowledge score was $7.75(\mathrm{SD}= \pm 1.81)$, while $60.4 \%$ of the respondents had average knowledge scores. Educational status $(\mathrm{P}=0.018)$ and designation $(\mathrm{P}=0.033)$ were significantly related to the mean knowledge scores. There was no significant difference in the oral health knowledge of the various cadres $(\mathrm{P}=0.393)$. Majority (85.4\%) of the respondents were willing to include oral health education in their job schedule and $82 \%$ believed they needed more training on oral health. The knowledge of the respondents on the causes of the common oral diseases was deficient. Oral health education should be included in the future curriculum of these personnel.

\section{Introduction}

Oral health is now considered an important and integral part of general health because poor oral health causes pain, discomfort, affects speech, ability to eat, sleep, self-esteem and confidence. Oral disorders may also result in increased morbidity and mortality, disfigurement and ultimately reduce the quality of life of the affected individual. In addition, a link has been established between poor oral health and various chronic non-communicable diseases such as diabetes, obesity, heart diseases, stroke, and cancers. ${ }^{1-7}$ It is also associated with low birth weight and the delivery of pre-term babies. ${ }^{8}$ The commonest oral diseases are dependent on and related to healthy diets devoid of refined carbohydrates, proper oral hygiene, healthy environments, adequate sanitation and clean water. Thus prevention is important in the management of dental diseases and establishing an integrated approach to general and oral health promotion is vital. ${ }^{7-10}$

Unfortunately, majority of the people residing in developing countries such as Nigeria do not have access to preventive oral health care $^{7}$ for a variety of reasons. This includes the fact that oral health services are few and poorly distributed and where available, they focus more on curative services. In addition, there is low supply of oral health personnel in the country coupled with the low oral health awareness among the populace. Consequently, the people who need preventive oral health services most such as the poor; especially in rural areas, pregnant women, children, the elderly, people with disabilities and people living with human immnunodeficiency virus (HIV) have limited access to such care. To improve access and reduce inequity to oral health care, suggestions have been made concerning the integration of oral health into general health care within the primary health care (PHC) system.

Many countries adopted the PHC system in 1978 after the declaration of Alma Ata. Initially oral health was not a component of PHC but it was later included alongside mental health. The inclusion of oral health in PHC promotes the use of less intensely trained personnel and appropriate technology. Nigeria adopted the PHC system in 1985 however oral health care is yet to be fully functional in the program. In Lagos state oral health care especially preventive oral health care is not provided at the PHC level. The high cost of training oral health personnel, inadequate infrastructure in the face of low budgetary allocation to health and escalating costs, inadequate oral health manpower led to calls for use of ancillary staff such as PHC workers to provide preventive oral health services. This is in addition to the global move away from curative to preventive oral health care, a focus on cost reduction and improving access to oral care. ${ }^{11,12}$ Furthermore, the recently adopted national oral health policy focuses on the integration of oral health with general health and identifies PHC workers as a veritable tool for achieving this. ${ }^{13}$ The PHC system provides the best opportunity to promote oral health as part of general health based on collaboration because most of the problems dealt with at the PHC level have an impact on oral health.

In Nigeria PHC workers include nurses, midwives, community health officers and community health extension workers (CHEW). In
Correspondence: Matilda 0. Braimoh, Dental Department, Lagos State University Teaching Hospital, Ikeja, Lagos State, Nigeria.

Tel +234.080.29293282.

E-mail: mattybraimoh@yahoo.com

Key words: primary health care, oral health, integration.

Contributions: MB, study conceptualizing, data collection, manuscript first draft; E0, critical appraisal and manuscript editing; AA, study conceptualizing, manuscript editing and critically appraising.

Conflict of interests: the authors report no potential conflict of interests.

Received for publication: 19 April 2013.

Revision received: 5 March 2014.

Accepted for publication: 5 March 2014.

This work is licensed under a Creative Commons Attribution NonCommercial 3.0 License (CC BYNC 3.0).

(c) Copyright M. Braimoh et al., 2014

Licensee PAGEPress, Italy

Journal of Public Health in Africa 2014; 5:328

doi:10.4081/jphia.2014.328

order to utilize PHC workers for preventive oral health care they need to have adequate oral health knowledge so as to furnish their patients with accurate and appropriate information and be willing to do the job. This study was thus designed to assess the knowledge of common oral diseases, to assess the perception of the importance of oral health as a component of PHC and to determine the willingness to manage common oral diseases among PHC workers in Lagos State. The results obtained will be useful in planning training programs for PHC workers in the state and updating their training curriculum concerning oral health with the possibility of including oral health promotion and prevention in their job description.

\section{Materials and Methods}

The study was carried out among the PHC workers in two local governments (one rural and one urban) in Lagos state. The Local Governments (LGs) were selected by simple random sampling method from a list of the 20 LGs in the state. There were a total of 27 primary health facilities in the two selected local government areas. Respondents included al nurse/midwives, community health officers and community health extension workers working in these facilities. The survey instrument was a well-structured questionnaire con- 
taining 3 sections with section one focusing on the respondents' demographic details, section two on their knowledge of common oral health diseases and oral hygiene habits, and section three on their views on the integration of oral health into PHC. The questionnaire was pretested and the reliability determined using a test-re-test method. A correlation coefficient of 0.63 was obtained.

A knowledge score was computed for each respondent based on the number of correct answers given to questions asked on the causes of the two common dental diseases, appropriate oral hygiene methods, importance of dental visits and the relationship between oral health and general health. Correct responses were scored as one (1) while incorrect ones were scored as zero $(0)$. The maximum possible score was 12 , the scores were graded as follows, and a score of 4 and below was graded poor knowledge, 5-8 average knowledge and 9-12 good knowledge respectively. Data entry and analysis was done using SPSS version 16 (SPSS Inc., Chicago, IL, USA; 2008). Quantitative data analysis was done using simple frequency counts. The chisquare statistical test was used for comparing proportions while the ANOVA test was used for comparing means. Multiple logistic regression was conducted to identify likely factors influencing the oral health knowledge of the respondents. The confidence interval was set at $95 \%$ and differences were considered significant at $\mathrm{P} \leq 0.05$.

\section{Results}

\section{Socio-demographic features of the study participants}

There were one hundred and seven (107) primary health care workers in the selected LG's and they were all included in this survey. Of the questionnaires administered, only 96 were returned giving a response rate of $89.7 \%$. The respondents' ages ranged from 20 to 58 years with mean (SD) of $38.70( \pm 7.97)$ while the mean (SD) years of experience was 13.02 $( \pm 8.14)$. Majority of the respondents were female (86.5\%), while about half (51.0\%) were nurses/midwives. Regarding educational status, $13.5 \%$ had obtained university education, $63.6 \%$ a diploma in nursing or community health while the remaining obtained certificate level training in community health.

\section{Respondents' previous dental experience}

Many of the respondents 60 (62.5\%) had never visited a dentist although more than three-quarters 76 (79.2\%) agreed that regular dental visits are necessary. Pain (58.3\%) was the commonest reason for visiting the dentist; only $10(27.8 \%)$ visited the dentist for a checkup (Figure 1).

\section{Respondent's perception on adequacy of their knowledge on oral health}

A total of 45 (46.9\%) respondents agreed that they were adequately informed on oral health while 51 (53.1\%) considered themselves inadequately informed or were unsure of the adequacy of their knowledge.

\section{Previous training on oral health and respondent's sources of information}

The sources of information on oral health were diverse but the most common source was from magazines and books 40 (41.7\%). Less than half of the respondents 41 (42.7\%) had received training on oral healthcare, while only 13 (13.5\%) respondents had received formal lectures. The lack of formal training on oral health did not appear to affect the knowledge scores of the respondents as only 5 (5.2\%) of them had poor scores $\mathrm{P}=0.140$.

\section{Oral health knowledge}

Table 1 shows the respondents' answers on questions on the causes of common dental diseases namely dental caries and periodontal disease. More than half of the CHEWs selected sugary foods as a cause of gum disease whilst only a few considered dirty mouth as a cause for gum disease and caries. When asked to mention two active constituents of toothpaste, the respondents mentioned calcium, fluoride, menthol, chloride, detergents, herbs, silica, water, vitamins, sugar and coloring. Fluoride was selected by 47 (49\%) respondents and calcium by $38(39.6 \%)$ whilst $8(10.8 \%)$ had no response.

\section{Factors affecting respondent's} oral health knowledge

The total knowledge scores obtained ranged from 4 to 11 with a mean knowledge score (and standard deviation) of $7.75( \pm 1.81)$. More than half of the respondents 58 (60.4\%) had average scores according to earlier described grading, 33 (34.3\%) good scores while only 5 (5.2\%) had poor knowledge scores.

The respondent's perception of the adequacy of their knowledge $(\mathrm{P}=0.465)$, previous training on oral health $(\mathrm{P}=0.140)$ were not significantly related to their knowledge scores (Table 2). However, it was significantly related to their educational status $(\mathrm{P}=0.050)$. Both educational status $\mathrm{P}=0.018$ and designation $\mathrm{P}=0.033$ were significantly related to the mean knowledge scores (Table 3). University graduates had significantly higher mean knowledge score than those with diplomas while community health officers had higher scores than nurses and community health extension workers. Logistic regression analysis identified

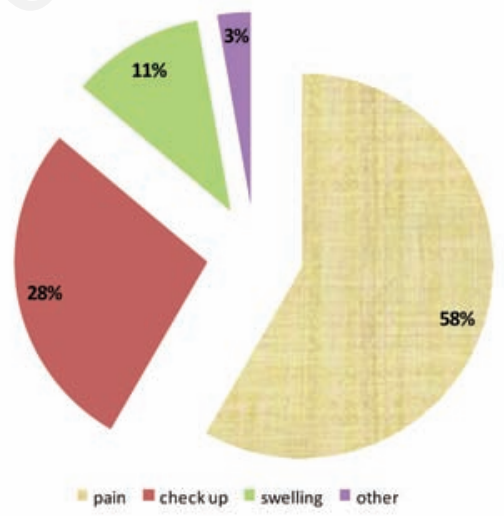

Figure 1. Respondents' previous dental experience.

Table 1. Responses to oral health knowledge questions.

\begin{tabular}{lccccc} 
Question & \multicolumn{2}{c}{$\begin{array}{c}\text { Correct } \\
\text { responses }\end{array}$} & \multicolumn{2}{c}{$\begin{array}{c}\text { Incorrect } \\
\text { responses }\end{array}$} \\
& No & $\%$ & No & $\%$ \\
Dirty mouth causes dental caries (F) & 71 & 74 & 25 & 26 \\
Worms cause caries (F) & 78 & 81.2 & 18 & 18.8 \\
\hline Sugary foods/drinks cause caries (T) & 61 & 63.5 & 35 & 36.5 \\
Bacteria/germs cause caries (T) & 48 & 50 & 48 & 50 \\
\hline Dirty mouth causes gum disease (T) & 72 & 75 & 24 & 25 \\
Worms cause gum disease (F) & 85 & 88.5 & 11 & 11.5 \\
\hline Sugary foods/drinks cause gum disease (F) & 48 & 50 & 48 & 50 \\
Bacteria/germs cause gum disease (T) & 48 & 50 & 48 & 50 \\
\hline Oral health can affect general health (T) & 85 & 88.5 & 11 & 11.5 \\
It is necessary to attend for routine dental check (T) & 76 & 79.2 & 20 & 20.8 \\
\hline Active constituent of toothpaste (F) & 47 & 49 & 49 & 51 \\
How many times should one brush daily for good oral health (Twice) & 50 & 52.1 & 46 & 47.9 \\
\hline
\end{tabular}

F, false; T, true. 
Table 2. Relationship between respondents' perception on the adequacy of their knowledge, formal training on oral health and their designation, educational status and graded knowledge score.

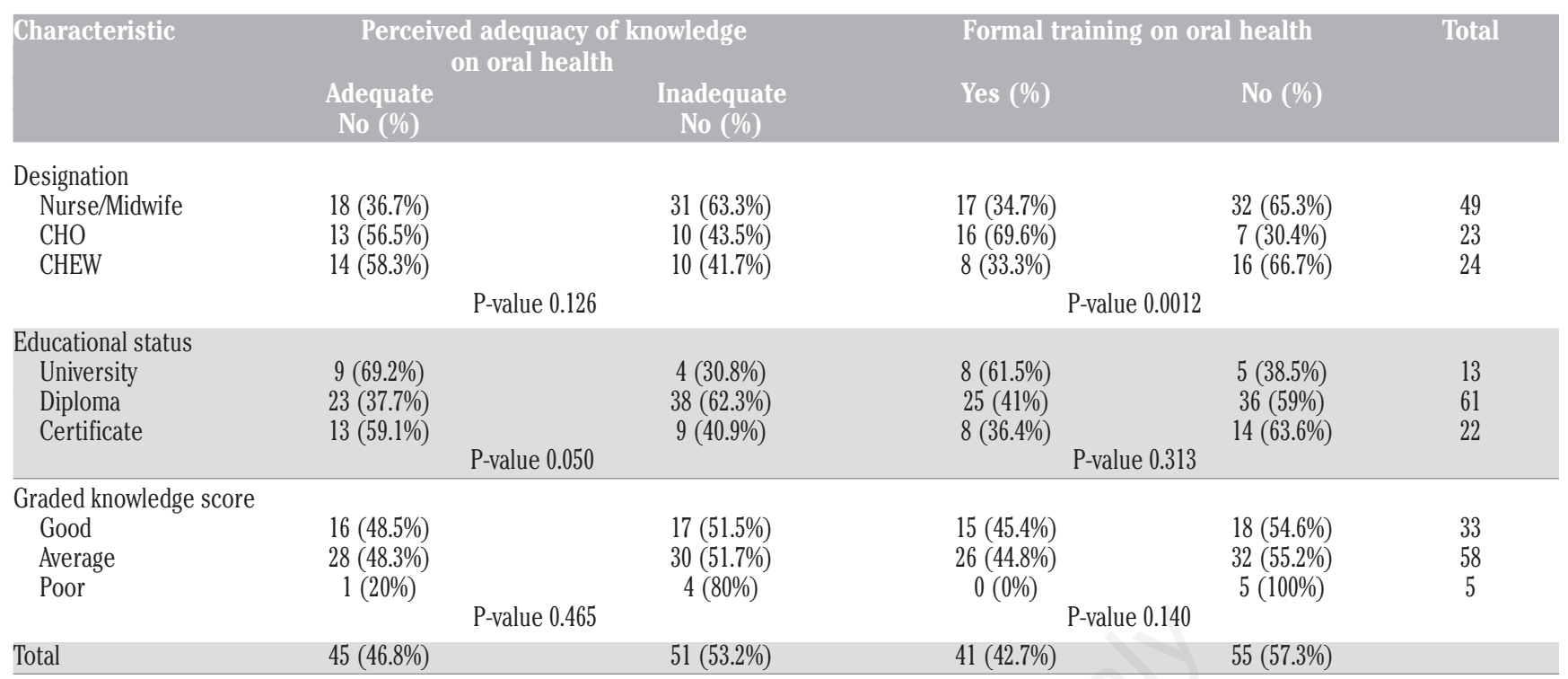

$\mathrm{CHO}$, community health officers; $\mathrm{CHEW}$, community health extension workers.

Table 3. Relationship between socio-demographic characteristics and knowledge scores.

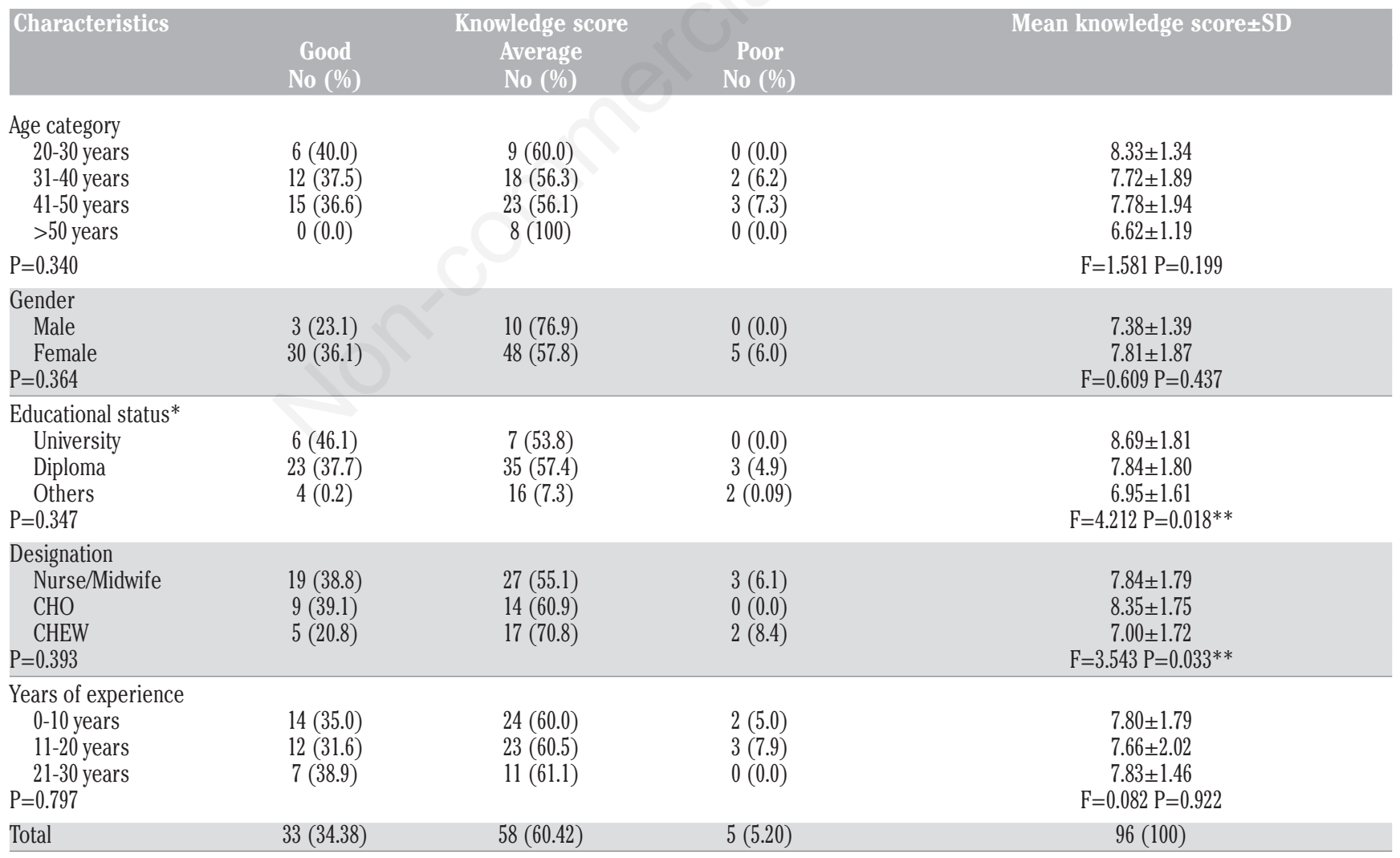

SD, standard deviation; $\mathrm{CHO}$, community health officers; CHEW, community health extension workers. *Average and poor scores were merged for computing the chi-square values; **statistically significant. 
location of practice and educational status as significant predictors of respondents' oral health knowledge (Table 4). Persons employed in urban areas were 1.2 times more likely to have good oral health knowledge than those employed in rural areas.

\section{Respondent's views on the integration of oral health into primary health care}

Majority of the respondents $85(88.5 \%)$ opined that oral health should be a part of PHC. Similarly, 82 (85.4\%) opined that oral health should be included in their work schedule. They suggested the integration of oral health into maternal and child health 83 (86.5\%) and nutrition clinics (76\%). Concerning personnel required to carry out oral health functions in PHC's majority suggested the use of existing PHC workers as best suited for the job. Various suggestions were made by the respondents on ways to include oral health. A total of 33 (33.4\%) respondents suggested giving health talks on oral hygiene and dietary habits, exclusive breast feeding and having regular dental check-up among others at the outpatients department, maternal and child health 29 (30.2\%) as well as nutrition clinics 29 (30.2\%)

The identified factors militating against the successful integration of oral health into PHC included shortage of personnel and high work load, lack of equipment and infrastructure, ignorance or inadequate knowledge and funding. The suggestions made for a successful integration of oral health into PHC were training of personnel, provision of equipment and adequate infrastructure, creation of an oral health unit in the PHCs with a focal person to handle all oral health matters. A high percentage of the respondents 77 (80.2\%) were willing to attend formal training on oral health with 30 (38.9\%) of these preferring short courses of between one and four weeks. Eighteen (23.3\%) were non-committal on the optimal length of training.

\section{Discussion}

The importance of oral health in the achievement of complete health can no longer be denied therefore there is a need to find ways of addressing the oral health needs of the Nigerian populace. The problem of inadequate personnel and rising costs of treatment brings to fore the importance of training adequate oral health personnel and the need for shortterm measures to bridge the gap. This led to suggestions for the integration of oral health and the use of allied personnel or ancillary staff in the PHC system especially since oral health education does not require highly

Table 4. Predictors of respondents' oral health knowledge.

\begin{tabular}{lcccc} 
Variable & Odds ratio & \multicolumn{2}{c}{$\begin{array}{c}\text { Confidence interval } \\
\text { Lower }\end{array}$} & $\begin{array}{c}\text { P-value } \\
\text { Upper }\end{array}$ \\
Gender & 1.241 & -0.954 & 4.390 & 0.434 \\
Local government & 1.248 & 0.518 & 1.979 & $0.001^{*}$ \\
\hline Educational status & 0.867 & 0.059 & 1.674 & $0.036^{*}$ \\
Years of experience & 0.016 & -0.030 & 0.062 & 0.489 \\
\hline Designation & 0.028 & -0.030 & 0.062 & 0.922 \\
Constant & 2.623 & -0.954 & 6.199 & 0.148 \\
\hline
\end{tabular}

*Significance 001. F=5.071.

skilled personnel. This agrees with suggestions made by various researchers ${ }^{9,12,14-29}$ on the use of less intensely trained personnel. Many opportunities exist for the members of the PHC team and voluntary workers to give advice on oral care. ${ }^{30}$

The fact that more than half of the respondents had never visited a dentist and only a handful had visited for a routine dental checkup suggests apathy towards oral health care and ignorance on the importance of routine dental check-up. It may also be an indication of limited access to oral health care. About half of the respondents were unsure of the adequacy of their knowledge. This perceived inadequacy could have been due to the fact that the major sources of information on oral health were mostly from magazines while only a few had formal lectures.

Studies have shown that the oral health content in the training curricula of nurses is deficient and inadequate ${ }^{22,23}$ and not given high educational priority. It has been reported that many health workers within the PHC system are ignorant of the oral complications of many systemic diseases and lack the required knowledge related to oral health. ${ }^{22-24}$ This highlights the need to assess and find ways to improve their knowledge through teaching modules and ongoing learning activities that will address the knowledge gaps identified and achieve a lasting effect. ${ }^{23,25-27}$

Overall, the nurses displayed better oral health knowledge than the community health officers and community health extension workers. This is probably because they are better educated; a few of the nurses 13 (13.5\%) had additional qualifications such as university degrees. Nonetheless, the knowledge of the study participants on oral health was unimpressive and this may be attributed to their source of oral health information. There is therefore a need to provide PHC workers proper tutelage on oral health if they are to serve as a veritable source of oral health information to PHC attendees.

Specifically, the knowledge of the respondents on the causes of the two most common oral diseases was deficient, as only about half of them knew that bacteria and germs cause caries. In respect of gum disease, half of the respondents also felt that sugary foods and drinks cause gum disease. Again the nurses/midwives made up about $60 \%$ of respondents who agreed that dirty mouth was a cause of caries. This result indicates that despite the seemingly better knowledge of the nurses, some of them are ignorant of the oral health issues. It suggests also that there is a gap in the knowledge of the causes of dental caries and they would still benefit from training on oral health issues. Past research on the knowledge of PHC workers on oral health also showed deficiencies in some areas and a relationship between education and level of knowledge. $^{29}$

Suggestions made on the best ways to integrate oral health into PHC were varied. Giving health talks at the antenatal, child welfare, nutrition and General Outpatient Department clinics were suggested as well as workshops/training on oral health care. Although all the suggested topics by the respondents are appropriate, there is the need to emphasize how each affects oral health in relation to general health condition. The shortage of and inadequate training of health personnel, lack of infrastructure and equipment as well as inadequate funding topped the list of factors militating against a successful integration This view on staff shortages and high workload, unavailability of physical structures and equipment as some of the problems of the PHC system is supported by some researchers. ${ }^{28,29}$

It is encouraging that most of the respondents agreed that oral health should be integrated into PHC. This shows a willingness to participate in the promotion of oral health care. This positive attitude would facilitate the process of integration. A good number of the respondents were willing to be trained though they preferred short-term courses. This is an acceptance by the respondents of gaps in their knowledge and a commitment towards change. Past studies have also shown that a four-hour education session has a positive influence on nurses' conception and knowledge of oral health. ${ }^{27}$ 


\section{Conclusions}

The result of this study reveals that PHC workers do not have adequate knowledge of common oral diseases and would thus benefit from training programs to enable them provide oral health care as an integral part of general health. These personnel can act as a source of information to the mothers and children on dietary habits, effect of nutrition on oral health, oral hygiene habits such as regular tooth brushing with fluoride toothpaste, tooth eruption times and help correct any cultural beliefs that impact negatively on oral health too. The PHC workers agree that oral health should be integrated into PHC, are willing to include oral health care in their job schedule and be given adequate and appropriate training.

\section{References}

1. Petersen PE. The world oral health report: continuous improvement of oral health in the 21st century - the approach of the WHO global oral health programme. Comm Dent Oral Epidemiology 2003;31:3-24.

2. Peterson PE. Improvement of oral health in Africa in the 21st century: the role of WHO global oral health program. Develop Dentistry 2004;5:9-20.

3. Beetstra S, Derkin D, Ro M, et al. Health commons approach to oral health for low income populations in a rural state. Am J Pub Health 2002;92:12-4.

4. Glick M. Exploring our role as health care providers, the oral medical connection. J Am Dent Assoc 2005;136:716-8.

5. Petersen PE, Bourgeois D, Ogawa $\mathrm{H}$, et al. The global burden of oral diseases and the risks to oral health. Bull World Health Organ 2005;83:661-9.

6. Watt RG. Strategies and approaches in oral disease prevention and health promotion. Bull World Health Organ 2005;83:711-8.
7. Osazuwa-Peters N. The Alma-Ata declaration: an appraisal of Nigeria's primary oral health care three decades later. Health Policy 2011;99:255-60.

8. Shanthi V, Vanka A, Bhambal A, et al. Association of pregnant women periodontal status to preterm and low-birth weight babies: a systematic and evidence-based review. Dent Res J (Isfahan) 2012;9:36880.

9. Sheiham A. Oral health, general health and quality of life. Int $\mathrm{J}$ Public Health 2005;83:644-7.

10. Petersen PE. The world oral health report 2003. Continuous improvement of oral health in the 21st century - the approach of the WHO global oral health programme. document WHO/NMH/NPH/ORH/03.2. Geneva: World Health Organization; 2003.

11. Jeboda S0. Integrating oral health care into PHC in Nigeria. Nig Dent J 1990;9:504.

12. Jeboda SO. An appraisal of Botswana's approach to provision of dental health services. Odontostomatol Trop 1984;7:75-8.

13. Federal Ministry of Health (FMOH). The national oral health policy. Abuja: FMOH; 2012.

14. Cane RJ, Butler DR. Developing primary health clinical teams for public oral health services in Tasmania. Austr Dent $\mathrm{J}$ 2004;49:162-70.

15. Sheiham A, Watt RG. The common risk factor approach: a rational basis for promoting oral health. Comm Dent Oral Epidemiol 2000;28:399-40.

16. Baine T. More oral health care for the ageing populations. Bull World Health Organ 2005;83:646-7.

17. Damiano PC. The Iowa oral health care reform workshop. J Dent Educ 1993;57: 923-4.

18. Homa E, Dolan C, Ramos-Gomez FJ, Mosca NG. Improving oral health integration within primary health care, 2005 Primary Health Care Policy Fellowship.

19. Khan AA, Ijaz S, Ayma S, et al. Oral health in Pakistan: a situation analysis. Develop Dentistry 2004;5:35-44.

20. Ogunbodede EO, Jeboda SO. Integration of oral health into existing PHC services in Nigeria - from policy to practice. Nig Dent J 1994;1:21-6.

21. Mautsch W. The Berlin oral health declaration, 10 years later: where are we now? Develop Dentistry 2003;1:1-3.

22. Longhurst RH. A cross -sectional study of the oral health care instructions given to nurses during their basic training. Br Dent J 1998;184:9.

23. Ogunbodede E0, Rudolph MJ, Tsotsi NM, et al. An oral health promotion module for the PHC nursing course in Acornhoek. South Africa. Public Health Nurs 1999;16: 351-8.

24. Sumi Y, Miura H, Nagaya M, et al. Colonisation on the tongue surface by respiratory pathogens in residents of a nursing home-a pilot study. Gerodontology 2006;23:55-9.

25. Amos A, Church M, Forster F, et al. A health promotion module for undergraduate medical students. Med Educ 1990;24:328-35.

26. Reeves S. Pryce A. Emerging themes, an exploratory research project of an interprofessional education module for medical, dental and nursing students. Nurse Educ Today 1998;18:534-41.

27. Paulsson G, Söderfeldt B, Fridlund B, Nederfors T. Recall of an oral health education programme by nursing personnel in special housing facilities for the elderly. Gerodontology 2001;18:7-14.

28. Manongi RN, Marchant TC, Byberg Ib.C. Improving motivation among PHC workers in Tanzania. A health worker's perspective. Human Resour Health 2006;4:6.

29. Abolghasem H, Tayebeh MM, Ebadollah H, Shahin S. Integrating oral health care into PHC system. ISRN Dentistry 2012;2012: 657068.

30. Watt RG, Fuller SS. Oral health promotion - opportunity knocks! Br Dent J 1999;186:3-6. 